\title{
Understanding experiential value creation at small-scale events: a multi-stakeholder perspective
}

Elaine Rust ${ }^{a * 1}$

${ }^{a}$ Geography and Environment, University of Southampton, Southampton, UK

elaine.rust@port.ac.uk*corresponding author

ORCid: https://orcid.org/0000-0003-0593-6599

Twitter@elainerust

7,320 words

\section{Data availability}

The data that support the findings of this study are available from the corresponding author, upon reasonable request.

\footnotetext{
${ }^{1}$ Now at Portsmouth Business School, University of Portsmouth, Portsmouth, UK
} 


\begin{abstract}
Although experiences gained from attending festivals and events are attracting academic interest, little study currently exists of this specific field (Geus, Richards, \& Toepoel, 2016). This empirical research seeks to contribute to the emerging area, by developing an understanding of how experiential value is co-created at small-scale cultural events, and in what form. In this paper, these events are characterised as markets or fairs typically located in a town centre setting, and with an audience of less than 10,000. These are also known as 'grassroots festivals'; defined as 'those that originate from within a community' (Platt and Ali-Knight, 2018, p. 262). Using case study methodology, qualitative data were collected from multiple stakeholders at three separate small-scale events in the UK: a folk music festival; a food festival; and a farmers' market, via semi-structured interviews, questionnaire surveys, observation and documentary analysis. Four determinants emerged as important influencers of the overall event experience: sense of belonging; atmosphere; place; and reputation, along with the concepts of authenticity (Jeannerat, 2013; Zukin, 2008) and immersion (Carù and Cova, 2006). When viewed in this holistic way, experiential value is revealed as a complex, yet delicate balance, which is easily disturbed. Policymakers and event planners need to take account of this in combination with local policy objectives when considering an events-focused economic development strategy. Experiential value created by a small-scale event in one location is not easily replicated elsewhere.
\end{abstract}

Keywords:, fairs, festivals, markets, market towns, experiential value.

\title{
Introduction
}

Events and festivals have been incorporated into economic development policy, 
sometimes as a standalone 'boosterist' (Hiller, 2000) strategy, for at least 25 years (Swyngedouw, Moulaert, \& Rodriguez, 2002). Quinn (2010), for example, remarks on the growth of arts festivals in particular, as a component of cities' attempts at reinvigoration or to increase economic activity. More specifically, cultural events are frequently found within local, regional or national tourism policy, as they provide opportunities for destinations to differentiate themselves from their perceived competition (Van Niekerk, 2017).

Aside from the potential to generate economic value, cultural events provide opportunities for out-of-the-ordinary shared experiences and can generate a sense of belonging (del Barrio, Devesa, \& Herrero, 2012; Getz, 1989). Event attendees do so based on the anticipation of enjoyment (Hoksbergen and Insch, 2016) which, according to Pine and Gilmore (2011), is one contributory factor to value creation, as it enhances the overall experience. In addition to attendees, other stakeholder groups, including event organisers, traders and performers, as well as local authority officers, play various roles in the creation of cultural events, each of which influences how any experience and therefore value - is generated, or co-created. Event organisers create the foundation for the experience by planning the event, facilitated by the local authority. Performers and traders interact with attendees to enable the experience to occur. These encounters provide opportunities for experiential value to be enhanced.

When analysing festival and event impacts, there has been a tendency to focus on economic benefits, whether this is for academic or policy-driven enquiry. In terms of the latter, at a local level, it seems easier to understand and report numbers, i.e. a tangible output, to local authority representatives. Research has, however, found that economic benefits for small-scale cultural events are minimal, with very little direct tourism impact (Rust, 2017). It is more difficult to report on the intangible outputs, 
such as emotions or well-being; so-called 'psychic income' benefits (Crompton, 2004; Kim and Walker, 2012). As a result, these are often overlooked at 'grassroots' (Platt and Ali-Knight, 2018) or community level, owing either to lack of understanding of how these other impacts are generated or insufficient resources. Attempts have been made to develop understanding of emotional benefits derived from major sporting events (e.g. Crompton, 2004; Kim and Walker, 2012), however, for small-scale cultural events, such as fairs, festivals or markets, less is currently understood.

The aim of this research is, therefore, to develop an understanding of how experiential value is co-created at small-scale cultural events by exploring the different factors that combine uniquely through the connections made between stakeholders, and the spaces and places in which the events are located. This study considers such events as festivals, markets or fairs, typically located in market towns and attracting an audience of less than 10,000 . In such a context, this contributes specifically to the emerging area of grassroots cultural events. From a policy perspective, it provides local decision-makers with evidence to aid their understanding of the different forms of experiential value that can be co-created by stakeholders through the medium of a cultural event. This will enable such policymakers to develop event-focused strategies that enhance a destination's attractiveness by capitalising on the potential to create experiential value.

\section{Small-scale cultural events and experience}

Richards and Palmer (2010) define cultural events as those which explicitly include a cultural component, such as music, arts or food. They take place at specific locations at set times, on a regular basis and have a celebratory element. They need a public audience, and various stakeholders both affect and are affected by them. Festivals have 
a place within this definition, which Getz (2007, p. 31) defines as 'themed public celebrations.' Gibson and Connell (2005, pp. 210-211) propose that festivals 'provide places with "spectacle" and a sense of "uniqueness", while Hall and Sharples (2008, pp. 9-11) describe them as 'celebration[s] of something the local community wishes to share and which involves the wider public as participants in the experience.' This notion is supported by Ferdinand and Williams (2013, p. 202), who suggest they are 'integral to all societies' as celebrations of cultural heritage and identity.

Events thus create experiences, which are never the same, no matter how many times one attends the same event (Richards and Palmer, 2010). These experiences can take different forms, for example, experiences of nostalgia (Holloway and Kneafsey, 2000), which can be generated by events such as farmers' markets, considered providers of a 'traditional social space' (Zukin, 2008, p. 735). These popular town centre events, are seen to offer an authentic experience (Hall, Mitchell, Scott, \& Sharples, 2008). This concept of authenticity is, however, a subjective notion, which is influenced by the positionality of the person engaged in the experience (Waitt, 2000): one person's perception of an authentic experience may vary greatly from another's. Authenticity in relation to events is, thus, a significant contributor to the way in which experiential value is created and is explored in more detail next.

\section{Experiences and authenticity}

Authenticity clearly influences the way in which experiential value is created, particularly in an event setting. Whilst providers are searching for opportunities to enhance consumer experiences, there is a risk that the activity or output could be viewed as a fabrication of reality and raises concerns over authenticity of experience. According to Jeannerat (2013, p. 378), this is the result of a direct connection between 
'market objects' and 'market actors' and is socially-constructed. When the influence of positionality is accounted for, authenticity is revealed to be more complex than simply considering whether the experience is perceived to be real or fake (Waitt, 2000). Waitt argues that the 'market objects', whether tangible or not, have narratives created for them by marketers as a means of creating distinction. These narratives are interpreted in different ways, dependent upon the knowledge and understanding of the recipient (Jeannerat, 2013). Different versions of authenticity, therefore, exist as 'in-themoment' experiences are entwined with the individual narratives of those immersed in the experience. Szmigin, Bengry-Howell, Morey, Griffin, \& Riley (2017) illustrate this through the vehicle of established music festivals, such as Reading, which are both temporally and spatially transient in nature: "placeless place[s] ... devoid of "real" inhabitants and "real" communities.' Authenticity emerges as a result of festival-goers' immersion, both in the festival and the place (Szmigin, et al., 2017). Thus, authenticity is a subjective construct: an 'imagined ideal' (Carù and Cova, 2007, p. 7). Experiences can be considered to be authentic simply because they match prior expectations (Waitt, 2000).

\section{Experiences, value and co-creation}

Slater and Wood (2015, p. 146) use emotion and memory to aid understanding of experiences created by cultural events. They observe that event attendance provides 'in-the-moment' experiences; a construct not dissimilar to the immersion proposed by Carù and Cova (2006, p. 5), defined as 'becoming one with the experience.' These emotions can be experienced by multiple stakeholders, not just event attendees.

Contributing to this argument, Dowell, Garrod, \& Turner (2019, p. 501) contend that cultural event organisers are the 'composers of value' and the event 
attendees' involvement acts as a medium for co-creation of the value. Missing from this is the part played by other actors in the process of value creation. This omission is addressed by Romero and Molina (2011, p. 449), who consider value creation to be a 'collaborative and co-evolutionary process with partners, allies, suppliers and customers that come together in close relationships within collaborative networks'. Although Romero and Molina refer to a business context, the principle can be easily transferred to cultural event stakeholders, who come together for mutual benefit. Shifting the context has an effect on the level of value co-creation and the way in which value is co-created (Horbel, Popp, Woratschek, \& Wilson, 2016).

Pine and Gilmore's (2011) exploration of the experience economy proposes that experiences are inherently connected with economic value. Understanding how to capitalise on the different types of experience relationship that exist or can be enhanced in a business context can increase competitive advantage in an often highly competitive environment. These principles translate to the medium of urban tourism destinations, such as market towns, that use their annual calendar of events to promote differentiation through the often diverse array of festivals. These may have connections to a historic event or activity, or a particular culinary item for which the place is renowned. In so doing, festivals can create distinctiveness of place, which helps to enhance experiences and, in turn, economic value. Further, market towns that are successful at attracting tourists are most likely to be in a position to capitalise on historic features (Powe and Hart, 2008). Place thus needs to be considered when exploring how experiential value is created in the context of small-scale cultural events.

The way in which experiential value can be created through the medium of a small-scale cultural event has been shown to be complex and is reliant on a number of externalities, including the location in which it is held. In the event and festival setting, 
all stakeholders can impact on each other's experiences but exactly how and to what extent is currently not well-researched. This is particularly the case for small-scale events that are typically used in in local economic development policy to enhance or create a local distinctiveness, in the hope of increasing economic activity for the destination.

\section{Methods}

\section{Research design}

This research was undertaken in association with Test Valley Borough Council (TVBC), a semi-rural local authority in the south of England, as a condition of the funding stream required collaboration with a non-academic external organisation. TVBC wanted to understand more about the various impacts of cultural events hosted within the borough, in order that this might guide future policy. The extent to which this involvement influenced the research is discussed at length in Rust (2017).

Case study methodology was selected for this empirical research, as it provided the opportunity for 'particularisation' (Stake, 2000) of a small number of individual cases. Since the aim of the research was to understand how experiential value was created at small-scale cultural events, this seemed to be the most appropriate approach, allowing greater depth of study within each case than might be feasible with other methods. This approach thus permits idiosyncrasies to emerge that might otherwise be overlooked.

A multi-stakeholder perspective was adopted for this research to develop a holistic understanding of how experiential value is co-created at cultural events. As previously stated, co-creation of value involves collaboration between all actors involved, regardless of standpoint (Romero and Molina, 2011). Consequently, all 
identified stakeholders were seen as contributors to any creation of experiential value. These were determined to be the event organisers, visitors, traders, performers, sponsors, local residents, town centre retail and service providers, local councillors and local authority officers.

The choice of case to include was influenced by TVBC, who requested that an event taking place in each of the borough's main urban areas of Romsey, Stockbridge and Andover were included. Initially, TVBC wanted analyses of annual events in these places, however, it became apparent during the early stages of the research that Andover did not host an annual event of any significance. After suggesting that Andover be excluded from the study, it became clear that all three towns needed to be included, for political reasons. As a result, a compromise was found, discussed later in this section. Although not an annual event like the other two, this action further strengthened the research by offering the potential for comparisons to be made and for a 'deviant' case to emerge (Silverman, 2011). The three events finally selected were: a folk music festival; a food festival and a farmers' and crafts market. Each took place on one day, within one of the aforementioned market towns. Events such as these in locations like these are typical of many that regularly take place across the UK throughout the year and are often used to promote these smaller urban places to attract tourists. The cases, therefore, provide a basis from which generalisations can be made. In addition, events like these illustrate and share a mixture of characteristics that differ from larger-scale cultural events, such as the music festivals studied by Szmigin, et al. (2017), as they occupy spaces within the host destination's town centre, whereas larger music festivals typically take place away from urban areas, for example, farmers' fields (e.g. Glastonbury Festival), largely owing to issues relating to noise and congestion. In addition, these smaller cultural events usually take place on one day and involve 
minimal set up and break down of equipment and physical structures. With numerous differences, the way in which experiential value is created may also differ.

\section{Case study context}

The Beggars Fair - Romsey

Romsey is a medium-sized market town that can trace its origins beyond the $10^{\text {th }}$ century abbey, around which the infrastructure has developed. The annual folk and roots music festival that takes place on the second Saturday in July has been running since 1993 in the town centre and adjacent recreation ground. The event is organised by a volunteer committee of local interested parties, which includes individuals, local businesses and community groups. A variety of musicians and performers occupy spaces along the town's medieval streets throughout the day and into the early evening, when performances move to the town's hostelries. Assorted temporary traders, including the local scout group, provide additional food and drink to alleviate excess demand on the town's own permanent provision. These stalls line the town centre streets, which are closed to through traffic for the day. The event is free to attend and performers are paid expenses only, yet they return year after year. It is promoted by TVBC in their tourist literature as one of the area's key annual events and attracts an audience of around 5,000 people.

[insert Figure 1]

\section{Trout 'n About - Stockbridge}

Stockbridge is a small rural market town, lying to the north-east of Romsey. The town has developed a reputation for trout fishing over the years and sale of fishing licences generates significant income for the local economy. The annual one-day food festival 
has taken place on the first Sunday in August since 2008 and currently consists of around 100 food-related stalls, tractor displays, musical performances and street theatre. Like the Beggars Fair, it is organised by a committee of local people, with the addition of a paid project manager. Any income surplus derived from stall rentals is awarded to local community groups on application, typically benefiting those that have representation on the committee or that provide volunteer support, for example, the local football club has provided car parking marshals in the past. As a result, the club was awarded a sum of money. The event is free to attend and attracts around 4,500 people, which for a population of less than 600 , can present a challenge with regard to the management of congestion. In terms of tourist promotion, TVBC considers this event to be its most significant cultural event.

[insert Figure 2]

\section{Andover Farmers' and Crafts Market}

Andover is the largest of the three market towns included here, both in terms of geographic spread and population size. Although the town has medieval roots, it experienced rapid expansion during the last half-century and is still subject to ongoing residential and commercial development. The farmers' and crafts market takes place on the third Sunday of the month between March and December. In addition to food, produce and craft stalls, occasional live music performances take place in a specific area known as the Time Ring. The market is positioned in the open air in front of the town hall, a location that would once have been the focal point, however, since the construction of a covered shopping centre in the 1970s, suffers from lower footfall.

Unlike the previous two cases, the market was initiated and is organised by the local authority in a direct attempt to support the town centre businesses, akin to the 
'boosterist' activities referred to by Hiller (2000) in relation to mega-events. The market was introduced by TVBC during the spring of 2014, in an attempt to increase footfall in the town centre on a traditionally quiet day and in response to concerns over the general decline in town centre retail. TVBC considers a farmers' market to be a suitable fit for a market town, particularly since Romsey regularly hosts its own, with success.

Although the preference was for an annual event to be included in this research, selecting one of any significance proved to be a challenge, and TVBC requested that the farmers' and crafts market be included. This may seem an anomalous event to include, however, the nature of its conception provides a line of enquiry that makes a considerable contribution to the overall study, not least of which is the opportunity to draw comparisons between the three different types of cultural event.

The contrived, rather than organic, nature of the Andover market raises questions relating to authenticity and how this might affect any experiential value. Given that this particular kind of cultural event is put in place by town centre managers or economic development officers in many towns across the UK, developing an understanding of whether there is a difference in the way the market is perceived by its stakeholders is a valid line of enquiry. For these reasons, this market serves as a deviant case and helps to strengthen the ability to generalise beyond three individual cases by offering a means of comparison (Silverman, 2011).

[insert Figure 3]

\section{Data collection and analysis}

Qualitative data were collected as they provide the opportunity to develop an understanding of a 'more holistic and contextualised picture' (Peperkamp, Rooijackers, 
\& Remmers, 2015, p. 147) than would be offered by quantitative methods. Data were collected via interviewer-administered questionnaire surveys and semi-structured interviews. The former comprised a mixture of approximately eight profiling and four open-ended attitudinal questions, the purpose of which was to determine likes, dislikes and behaviours concerned with the events, for example, 'what do you like about [event]?' The questions were deliberately vague, in order to avoid any unintended bias or compliance (Bryman, 2016). These were completed by event visitors, local businesses, event traders/performers and local residents. The semi-structured interviews were conducted with event organisers, sponsors, local government officers and councillors, and lasted between 30 to 90 minutes, depending on how open the interviewees were with their responses. A schedule was used to direct the interviewees towards explaining their role, both within their organisation and in respect of the event, as well as their attitudes towards the events. All interviews were recorded using a digital voice recorder and transcribed verbatim by the author, in order to capture as much rich data as possible, including inflections or emotions exhibited vocally and, thus enhance the ability to understand the 'essence of the experience' (Peperkamp, et al., 2015, p. 147) reported by the respondents. A combined total of 778 separate responses were obtained, identified in Table 1. This mixed approach was taken in order to maximise opportunities to obtain responses from larger groups, while retaining the ability to obtain detail from the smaller stakeholder groups.

[Table 1 near here]

The survey data were initially entered into Excel spreadsheets and the interviews transcribed into Word files by the author, as this ensured a consistent approach throughout. These files were subsequently autocoded using NVivo to facilitate analysis by grouping responses according to the question asked. Data were interpreted by the 
author using thematic coding, a commonly recognised method for this type of research (Bryman, 2016), specifically through application of the process recommended by Robson and McCartan (2016) for interpreting and presenting large amounts of qualitative data (see Table 2).

[Table 2 near here]

\section{Results and discussion}

Four key themes emerged from the data analysis, which are discussed individually and then considered alongside the concept of authenticity to broaden understanding of how experiential value can be created at small-scale cultural events located in town centres.

\section{Belonging: 'insiders' and 'outsiders'}

Crompton and McKay (1997, p. 425) argue that event attendance is motivated by 'a desire to meet a need', whether this is physical or emotional. This might be, for example, to view a specific musical performance (Nicholson and Pearce, 2001). Alternatively, there may be a wish to feel emotional connectivity by sharing a similar experience with likeminded people; to feel as though one is part of a particular social group (Hawkins and Ryan, 2013; Richards and Palmer, 2010). Cultural events provide a platform for out-of-the-ordinary shared experiences and can cultivate a feeling of belonging (del Barrio, et al., 2012; Getz, 1989).

This sense of belonging emerged in three key ways: first, the local feel of the events; second, the community spirit woven into the events; and third, as the events provided a forum to share experiences with family or friends. The experience seemed to be enhanced by the feeling of being an 'insider,' through all stakeholders being involved in sharing a common experience, which was expressed in a variety of ways: from the farmers' market stallholder who enjoyed meeting and talking to the attendees, 
as they could 'build up a good relationship' with them; the food festival visitor who was keen to support local producers; or the local independent retailer who felt that it was important to open and show support for the event even though they knew they would not make many sales that day. This sense of belonging also extended to the music festival performers, one of whom commented that it was a 'key part of our musical year. We turn down other festivals to be here.' A sponsoring organisation's employee illustrated the strength of connection by commenting '.. but it's kind of not just about that event, it's about the actual whole town itself ... that we all do work for.' These and other remarks indicated that there was a strong emotional benefit derived from this feeling of becoming an integral part of the event and the place, even for a short period of time. Strangers would interact with one another to enjoy a shared experience.

The events were also used as opportunities for unplanned encounters. One respondent observed in respect of the Beggars Fair, 'it's a very social event, I might see somebody I know,' indicating that no plans were made in advance to meet friends or acquaintances. This was repeated at the farmers' market, with another respondent reporting, 'it's a social thing really. We don't need to buy anything, it's just nice to bump into people we know.'

Quinn and Wilks (2013) observe that festivals have a binary nature: one either attends or does not, thus, they are either inclusive or exclusive. Richards and Palmer (2010) additionally argue that it is the nature of this exclusivity that heightens the sense of belonging: that being an 'insider' is preferable to being an 'outsider.' By developing a sense of belonging whilst attending the events, whether a visitor, trader, organiser or sponsor, experiences are enhanced, contributing to the co-creation of value.

Exclusion was also evident, and this emerged in two ways: either self-imposed, in that the event was something with which the respondent did not want to feel 
associated; or that the respondent did not consider themselves able to participate for various reasons. In terms of self-imposed exclusion, a public disturbance, which occurred at the Beggars Fair some years previously, provided sufficient reason for some to disassociate themselves: 'I just don't think it's "Romsey." It attracts undesirables why do we want that and the trouble it brings?'

Disillusionment with an event that does not conform to expectations was also a contributor to self-exclusion. This featured most in relation to the farmers' market. As one resident commented; 'I was disappointed with low stall turnout.' Another suggested there was a mismatch between the expectations created by promotional activity and the reality: 'I have been quite disillusioned by the marketing.'

The other type of exclusion aligned more with social exclusion, that somehow the respondent felt as though they were an 'outsider' and, therefore, the event was not something they could access. This might be for physical or emotional reasons. In terms of the former, one resident of Stockbridge indicated their mobility prevented them from visiting Trout 'n About: 'I only get out when someone takes me in my wheelchair and I never go to Trout ' $\mathrm{n}$ About, as it is impossible to get through the crowds with a wheelchair.' Further, perceptions of inflated prices also weakened experiential value. Although some felt that simply attending the event was enough for them to obtain experiential value, others felt 'guilty at not buying anything,' while this perceived barrier prevents some residents from visiting: 'Due to the price they tend to attract a certain type of customer, which makes the atmosphere quite snobby.' This comment relating to the farmers' market suggests that the respondent felt like an outsider in their own place of residence. In an attempt to enhance the vibrancy of the town of Andover and to increase footfall on a quiet day, the local authority has created an air of exclusivity. 


\section{Atmosphere}

'Atmosphere' is difficult to define in the context of cultural events, however, Getz (1989, p. 127) has described it as a combination of tangible and intangible components that contribute to the visitor experience, which 'makes events special', and meets attendees' expectations of enjoyment. Thus, it is another component of the emotional needs referred to previously. Atmosphere is also referred to in the literature as the emotions or feelings associated with an event, for example, 'party atmosphere' or 'community atmosphere' (Kim and Walker, 2012, p. 97); 'festival atmosphere' (Burgan and Mules, 1992, p. 709); 'atmosphere of acceptance and conviviality' (Pennay, Manton, \& Savic, 2014, p. 1093). Adjectives like these suggest a pleasant or positive experience, as referred to by Pine and Gilmore (2011); something Hart, Grayzna, Mohammed, \& Laing (2014) have deemed to be an important contributor to attracting visitors to town centres. This convivial atmosphere can be thought of as Crompton's (2004) 'feel good factor' in the psychic income approach proposed as a means of understanding the less quantifiable impacts of events.

The atmosphere or ambience associated with the events featured as an important factor in enhancing the overall enjoyment and, in this way, acted as a contributor to experiential value. Each stakeholder seemed to play their part in co-creating this pleasant atmosphere, from the local authority officer, who chatted to the market traders while they set up their stalls, offering official support and advice if needed, to the market trader who enjoyed exchanging conversation with their customers, mentioned above.

The word 'atmosphere' was either used explicitly in conjunction with other positive adjectives, such as 'casual atmosphere and friendliness' and 'the wonderful carnival street party atmosphere of the whole town', or implied: 'it's just a really 
general good feeling around the place;' 'the buzz of people enjoying themselves.' Each of these comments indicated that the atmosphere made an important contribution to the level of enjoyment felt by the stakeholders.

Evidence of negative attitudes relating to atmosphere were equally important in terms of experiential value and detracted from levels of enjoyment reported. Concerns over the effects of congestion, whether pedestrian or vehicular, featured particularly for Trout ' $\mathrm{n}$ About, which is located along both sides of a broad Georgian high street. Some felt that the local authority should close the road to allay safety fears, but TVBC is unable to implement this owing to the nature of the road.

Fears of anti-social behaviour seemed to impact on respondents' perceptions of the atmosphere. Those who witnessed such behaviour felt that this changed their levels of enjoyment. In particular, concerns over excess alcohol consumption by some event attendees contributed to altering the 'atmosphere around the pubs, doesn't feel safe. Police make me feel less safe because they shouldn't be needed.' Thus, indicating that the presence of the police suggests problems may occur, which increases levels of concern and then generates the feeling of a worrying atmosphere.

\section{Place}

Richards, de Brito, \& Wilks (2013) have argued that cultural events enable people to create their own connections to place. This factor emerged frequently in two respects: first, place in the locational sense and, second, in terms of the spatial layout of the events within their host towns. Connected to place, heritage and history also featured. Combined, these factors contribute to experiential value and are created collaboratively by all stakeholders. 
In the locational sense, the physical setting for cultural events is important, with some places being more capable of creating experiential value than others. All three cases took place in what were once well-established market towns, with numerous fairs and markets operating throughout the year and so were important focal points for their respective communities. For a variety of reasons, the reliance on these regular fairs and markets has diminished over the centuries. The reasons for the creation of the case study events included here are varied and so too are the connections to their host towns. These connections have an impact on how the experiential value is created for the event stakeholders.

The first two cases were located in towns that are well-suited to attracting visitors, in that they are able to make good use of their existing heritage, which is largely unaltered by modern developments (Powe and Hart, 2008). Characteristics of these places emerged as part of the attraction to the event, for example, one respondent included the 'lure of Stockbridge' as a motivator for attending. The combination of the event and the market town was considered to be 'quintessentially English.'

In contrast, the farmers' market struggles to emulate similar levels of attraction. The town itself has suffered from rapid development during the last half-century, with the construction of a covered shopping centre offset from what would once have been the focal point of the town, where the town hall - now a café - is situated. In addition, there has been much industrial and residential development beyond the town centre, engulfing what remains of the historic past. As a result of this modern expansion, Andover seems to have lost much of the character it once possessed and the image of a traditional market town, such as is evident in Romsey and Stockbridge, is absent. Andover seems to struggle to make any connection with the past to work to its full advantage today. Nevertheless, TVBC considers it to be a market town in that it 
maintains its weekly charter market. The perception of the place seems to discourage visits to the farmers' market, as one resident remarked: 'Unfortunately, the town centre has been allowed to degenerate because of the quality of shops ... This makes us avoid the town centre, apart from essential shopping.'

The second way place emerged as a factor is reminiscent of Pine and Gilmore's (2011) 'aesthetics'; one of their four realms of experience. It refers to the spatial configuration of the events and how they are incorporated into their host town's existing infrastructure in this context. The medieval street pattern of Romsey contributed to enhanced positive experiences, since the narrow lanes lined with buildings act as sound barriers, enabling many acts to perform simultaneously with minimal conflict of sound. It also enabled visitors to 'wander around and find different tunes happening in different places.'

The existing infrastructure can also act as a hindrance. The Trout ' $\mathrm{n}$ About stalls are positioned along both sides of a trunk road, which cannot be closed, as there is no obvious or convenient diversion. The area in which the farmers' market is located can also be challenging, as it acts as a wind tunnel and causes traders problems on occasion, as they struggle to prevent their gazebos and products from blowing away.

\section{Reputation}

The contribution made by reputation has been touched upon previously in this discussion and thus, demonstrates its importance in how experiential value is created for stakeholders. Reputation emerged in two ways: first, reputation of the event and second, reputation of the place. Bradley and Hall (2006) have remarked that the public image of a town can be enhanced by a cultural event, and this seems to be the case for two of the events studied here, however, an event's prior reputation can also be 
sufficient for it not to be welcomed (Hubbard, 2013). Anti-social behaviour, or perceptions of it, has the ability to tarnish an event's reputation more than any other negative attribute, such as congestion or noise pollution (Deery and Jago, 2010).

As discussed earlier, the first two cases are already considered to be popular events located in popular destination market towns, benefiting from features identified by Powe and Hart (2008). The events have a synergy with their host towns and profit from a reputation based on the existing image of their host towns. Equally, the host towns benefit from the reputation created by the events and, in this way, contribute to enhancement of experiential value for the event stakeholders.

Perceptions of poor reputation can also cloud any experiential value that might be created. This refers both to the event and the place. Evidence from the Beggars Fair indicates that memories of anti-social behaviour incidents remain at the forefront of people's minds for years after the behaviour occurred and that memories become distorted. It emerged that there was a serious incident at the 2011 event, involving an alcohol-related fracas, which led to police intervention. One respondent indicated that they thought it happened two years later. This perception of drunken behaviour featured frequently and was mentioned by all stakeholders involved in the research. Some downplayed it, while others used it to defend their lack of desire to be involved. Despite multiple stakeholders working together to find a solution to minimise such behaviour, this perception endures, which impacts on the broader reputation of the event and confirms the views of Deery and Jago (2010). It has also, in some quarters, created a reputation for the town.

The reputation of the place can also detract from experiential value creation. As mentioned previously, there is a perception that Andover is a town that struggles to attract visitors and the farmers' market was a deliberate attempt by the local authority to 
increase footfall. Any reputation that the market is attempting to build appears to be undermined by the pre-existing reputation of the town. There is, however, a feeling of anticipation among local businesses that its introduction will eventually generate interest in the place, with some respondents expressing gratitude for TVBC's attempt. An impression of an uninspiring town was, nevertheless, evident, particularly from residents who chose not to attend the market. This perception of a town with little to offer prospective visitors may outweigh any attraction the market is able to provide. In this way, the town's reputation damages the market's reputation, detracting from any potential experiential value. This extends Bradley and Hall's (2006) earlier observation regarding a town's public image, by illustrating the opposite: that the reputation of a cultural event can be damaged by the public image of a town.

\section{Immersive experiences and perceptions of authenticity}

Although not expressly referred to above, there is an implicit suggestion that leads to questions concerned with perceptions of authenticity and how such perceptions may affect levels of experiential value. Here, authenticity and its association with immersive experiences are explored to explain this in more detail.

Authenticity of experience has already been considered to be a subjective, social construct (Jeannerat, 2013), influenced by the personal narratives and preconceptions of the consumer of that experience (Waitt, 2000). Different versions of authentic experiences, therefore, exist. Szmigin, et al. (2017) have contended that attending a festival is sufficient for it to provide an authentic experience, however 'authentic' is interpreted by the festival-goer. This is Tope et al's (2005, p. 483) notion of 'being there', or Carù and Cova's (2006) theory of immersion in an experience. 
In terms of the three case studies examined in this research, each provides its own level of authenticity. If, as observed by Arthur and Hracs (2015), place is a significant contributor to the quality of the immersive experience, then that aids understanding of how the events in this research might be considered authentic or inauthentic. The maintenance of the historic character of at least two of the host towns contributes to the authenticity of the events they host. It seems perfectly reasonable that a folk festival should be held in a historic market town, and with a name like the Beggars Fair, there is a suggestion that the event may have some link to the past. Understood in this way, the Beggars Fair can be considered authentic, as it complies with visitor expectations (Waitt, 2000). The reality is, however, quite different, as the name is the creation of the organisers, who thought it sounded similar to an established and successful annual arts festival in a nearby town. Despite this, no evidence emerged to suggest that there was a perception of contrived authenticity, or that the Beggars Fair was considered to be fake in any way.

The farmers' market serves as a 'deviant case' (Silverman, 2011) here in relation to authenticity. In as much as the Beggars Fair appears authentic for the reasons discussed, the farmers' market does not. Whilst it seems plausible to locate a farmers' market in a market town, there appears to be a disconnect in this particular case. This disconnect appears to detract from any experiential value that might be created overall. Andover appears to be a place that is not a popular destination, if recorded footfall is used as an indicator. Town centre businesses need support, particularly since the town suffers from some long-term vacancies. To provide a solution to this problem, TVBC has attempted to replicate the style of event that functions well in Romsey and Stockbridge. From TVBC's perspective, a farmers' market ought to be a natural feature, so in theory is authentic. In turn, visitors searching for an authentic experience 
would expect to see a farmers' market in a market town (Zukin, 2008). The reality, however, is that the historic character of the town is now virtually non-existent, owing to the $20^{\text {th }}$ century expansion and confirms the findings of Powe and Hart (2008), discussed previously. The attempt to perpetuate a historic market town image is misplaced in a largely modern town, so any anticipated value that might be attributed to enhanced experiences based on the authenticity of the place and the cultural event is lost.

\section{Co-creation of experiential value}

Romero and Molina (2011) have argued that co-creation involves collaboration with all stakeholders, which was confirmed by the research. All stakeholder groups involved with the Beggars Fair and Trout 'n About demonstrated an enthusiasm to co-operate with each other, for example the organising committees of both included members of local community organisations, businesses, the local authority, sponsors, police and local authority. Some were also local residents. There was a clear desire to be involved, as illustrated by some of the comments included in earlier sections.

Collaboration was also demonstrated by the involvement of community groups on the day of the events: the scout group providing a barbeque at the Beggar's Fair and the local football club organising the car parking at Trout ' $\mathrm{n}$ About. These two cases illustrate clearly that the holistic combination of stakeholders is a key component of how the events are viewed and experienced by all of them.

The farmers' market presented as an entirely different and, thus, 'deviant' case (Silverman, 2011) in terms of demonstrating how experiential value is co-created at small-scale cultural events. Indeed, it served to demonstrate how experiential value is weakened through the absence of collaboration. Aside from the temporal difference, 
that it is a monthly rather than annual event, other differences that emerged from the research contributed to the construction of barriers to the effective creation of experiential value. The lack of community involvement was perhaps the most apparent. The disparate nature of community structures, owing largely to the way in which the residential development has occurred over recent decades may be one factor. Other aspects, such as the lack of commitment from town centre businesses to open on Sundays when the market operates could be another factor, however, lack of communication between the market organiser and these businesses seemed to create friction. These factors were summed up by one stakeholder, who remarked: 'Andover seems to be the place, for whatever reason, that things don't take off - everything just fizzles out and so, therefore, there's a great deal of scepticism about starting something new.' It is possible that the lack of collaboration between stakeholders in this particular case is a significant contributor to the reduction of experiential value for all stakeholders.

Slater and Wood's (2015, p. 146) 'in the moment' experience was, however, evident across all stakeholders, including the farmers' market, as market traders valued the involvement of the local authority officer who also acted as market manager on the day. Further, the local businesses acknowledged TVBC's good intentions to increase footfall by introducing the market in the first place.

\section{Conclusions}

Pine and Gilmore (2011) have claimed that experiences are key to enhancing economic activity in an increasingly commoditised world. This research has explored the concept using the vehicle of small-scale cultural events and proposes that experiential value in such contexts is influenced via four key factors: sense of belonging; atmosphere; place 
and reputation. The results suggest that when combined, these factors create a holistic experience, however, individually, each has the potential to enhance or detract from any overall experiential value that may be created.

This research confirms Horbel et al's (2016) findings; that value co-creation is context-specific. It broadens the argument and contributes further to theoretical debate by observing that spatial and geographical contexts also influence the way in which experiential value is co-created. In general terms, the type of event and the type of location studied here provide the environment for experiential value creation, but the level of value that is or can be created is deeply embedded in specific contexts. A farmers' market in a location that may once have been a thriving market town, for example, may not provide the forum for experiential value creation that theoretically it should. These contexts are built around local narratives featuring perceptions of authenticity, which, owing to the nature of its subjectivity (Jeannerat, 2013; Waitt, 2000) can alter dependent on the positionality of all stakeholders concerned with the event.

Numerous monthly farmers' markets and annual food or music festivals take place in similar market towns across the UK, with comparable stakeholder involvement. Many small to medium-sized market towns remain relatively untouched by modern development - like Stockbridge and Romsey - however, there are many - like Andover - that have suffered from modern inbuilding and expansion, thus altering the historic characteristics. As such, the cases explored in this paper are representative and the research thus makes a practical contribution for policymakers and practitioners to consider when planning a cultural events programme. Individual contexts are significant influences on the ability of a cultural event to create experiential value, as demonstrated by Andover farmers' market. In this particular case, those responsible for 
planning the market should make every effort to encourage communication and involvement with all stakeholders, as this would increase the ability to enhance each of the identified factors. More generally, stakeholders should work towards balancing the four factors of belonging, atmosphere, place and reputation in order to maximise the potential for experiential value creation. Clearly, the level to which they are able to achieve this is dependent upon the priorities and perspectives of individual stakeholders, for example, a non-attending resident will have little ability to influence the atmosphere of an event from which they are absent.

These findings provide a platform for further enquiry centred on how experiential value is created at small-scale cultural events; an often-overlooked area in the broader field of events study. In particular, of the four factors identified here, it would be beneficial to learn whether one is more prominent than another and how different stakeholders view their relative importance.

\section{Limitations}

This study involved in-depth analysis of three cases in three separate market towns, each located within the same local authority area. As a result, there is a risk of homogeneity or bias. This was accounted for with the introduction of a deviant case, however, the findings would be strengthened through further study in separate locations to test their validity. Different data collection methods would further enhance this, for example by conducting focus groups for each set of stakeholders in order to gain further understanding of how the four emergent factors contribute to experiential value creation.

\section{Acknowledgements}

This work was supported by the ESRC under Grant number 1077428 and Test Valley 
Borough Council.

The author would like to thank Test Valley Borough Council, the respective town councils and event organisers for permitting access to conduct this research.

\section{Declaration of interest statement}

The author has no affiliation to Test Valley Borough Council, nor any of the case studies included.

This paper draws from the author's $\mathrm{PhD}$ thesis and, consequently, some content has been replicated. 


\section{References}

Arthur, I. K., \& Hracs, B. J. (2015). Experience the Difference: The Competitive Strategies of Food-Related Entrepreneurs in Rural Denmark. [Article]. Geografiska Annaler Series B-Human Geography, 97(1), pp. 95-112. doi:10.1111/geob.12067 Retrieved from < Go to ISI>://WOS:000353049500006 http://onlinelibrary.wiley.com/doi/10.1111/geob.12067/abstract http://onlinelibrary.wiley.com/store/10.1111/geob.12067/asset/geob12067.pdf? $\mathrm{v}=1 \& \mathrm{t}=\mathrm{j}$ 5thwe4u\&s=5293a8cbe35acd1102e7c5fcab98b184b431c4cb

Bradley, A., \& Hall, T. (2006). The Festival Phenomenon: festivals, events and the promotion of small urban areas. In D. Bell \& M. Jayne (Eds.), Small Cities: urban experience beyond the metropolis (pp. 75-90). Abdingdon: Routledge.

Bryman, A. (2016). Social Research Methods (5th ed.) Oxford: Oxford University Press.

Burgan, B., \& Mules, T. (1992). Economic impact of sporting events. Annals of Tourism Research, 19(4), pp. 700-710. doi:10.1016/0160-7383(92)90062-t Retrieved from http://www.sciencedirect.com/science/article/pii/016073839290062T

http://ac.els-cdn.com/016073839290062T/1-s2.0-016073839290062Tmain.pdf? tid=e6a471e77d746d50e10344cbcbb2c4ac\&acdnat $=1335804382 \quad 3394 \mathrm{e} 48 \mathrm{a}$ 81ee12b4192c94e4c35b5741

Carù, A., \& Cova, B. (2006). How to facilitate immersion in a consumption experience: appropriation operations and service elements. Journal of Consumer Behaviour, 5(1), pp. 4-14. doi:10.1002/cb.30

Carù, A., \& Cova, B. (2007). Consuming Experience Abingdon: Routledge.

Crompton, J. L. (2004). Beyond economic impact: An alternative rationale for the public subsidy of major league sports facilities. Journal of Sport Management, 18(1), pp. 40-58. Retrieved from <Go to ISI>://WOS:000188662400003

Crompton, J. L., \& McKay, S. L. (1997). Motives of visitors attending festival events. Annals of Tourism Research, 24(2), pp. 425-439. doi:10.1016/s01607383(97)80010-2 Retrieved from < Go to ISI $>$ ://WOS:A1997WL80800010

http://ac.els-cdn.com/S0160738397800102/1-s2.0-S0160738397800102main.pdf? tid=1634e29906965dee50ffed867444f8a9\&acdnat $=1334592574 \quad 24 \mathrm{a} 922654$ 788d011c2586fda97ec7a94

Deery, M., \& Jago, L. (2010). Social impacts of events and the role of anti-social behaviour. International Journal of Event and Festival Management, 1(1), pp. 828.

del Barrio, M. J., Devesa, M., \& Herrero, L. C. (2012). Evaluating intangible cultural heritage: The case of cultural festivals. City, Culture and Society, 3(4), pp. 235244. doi:http://dx.doi.org/10.1016/j.ccs.2012.09.002 Retrieved from http://www.sciencedirect.com/science/article/pii/S1877916612000501

http://ac.els-cdn.com/S1877916612000501/1-s2.0-S1877916612000501main.pdf? tid=2eab7710-a7c0-11e4-a2ab00000aacb361\&acdnat $=1422540638$ b6cb58ef7d9c4ea8dfb074f84bb27436

Dowell, D., Garrod, B., \& Turner, J. (2019). Understanding value creation and word-ofmouth behaviour at cultural events. The Service Industries Journal, 39(7-8), pp. 498-518. doi:10.1080/02642069.2019.1568997 Retrieved from https://doi.org/10.1080/02642069.2019.1568997

https:/www.tandfonline.com/doi/full/10.1080/02642069.2019.1568997 
Ferdinand, N., \& Williams, N. L. (2013). International festivals as experience production systems. Tourism Management, 34(0), pp. 202-210. doi:http://dx.doi.org/10.1016/j.tourman.2012.05.001 Retrieved from http://www.sciencedirect.com/science/article/pii/S0261517712000891

http://ac.els-cdn.com/S0261517712000891/1-s2.0-S0261517712000891main.pdf? tid $=04454438$-94cf-11e3-aede00000aab0f6b\&acdnat $=1392310440 \quad 5174731526 \mathrm{db} 193 \mathrm{fdd} 583 \mathrm{e} 5442 \mathrm{eff507}$

Getz, D. (1989). Special events: Defining the product. Tourism Management, 10(2), pp. 125-137. doi:10.1016/0261-5177(89)90053-8 Retrieved from http://www.sciencedirect.com/science/article/pii/0261517789900538

Getz, D. (2007). Event studies theory, research and policy for planned events Oxford: Butterworth-Heinemann, an imprint of Elsevier.

Geus, S. D., Richards, G., \& Toepoel, V. (2016). Conceptualisation and Operationalisation of Event and Festival Experiences: Creation of an Event Experience Scale. Scandinavian Journal of Hospitality and Tourism, 16(3), pp. 274-296. doi:10.1080/15022250.2015.1101933 Retrieved from https://doi.org/10.1080/15022250.2015.1101933

Gibson, C., \& Connell, J. (2005). Festivals: Community and Capital. In C. Gibson \& J. Connell (Eds.), Music and Tourism : On the Road Again (pp. 262-271). Clevedon: Channel View Publications.

Hall, C. M., Mitchell, R., Scott, D., \& Sharples, L. (2008). The Authentic Market Experience of Farmers' Markets. In C. M. Hall \& L. Sharples (Eds.), Food and Wine Festivals and Events Around the World (pp. 197-231). Oxford: Elsevier.

Hall, C. M., \& Sharples, L. (2008). Food and Wine Festivals and Events Around the World Oxford: Elsevier.

Hart, C., Grayzna, S., Mohammed, R., \& Laing, A. (2014). The Customer Experience of Town Centres. Loughborough

Hawkins, C. J., \& Ryan, L.-A. J. (2013). Festival spaces as third places. Journal of Place Management and Development, 6(3), pp. 192-202. doi:10.1108/jpmd-022013-0002

Hiller, H. H. (2000). Mega-events, urban boosterism and growth strategies: An analysis of the objectives and legitimations of the Cape Town 2004 Olympic bid.

International Journal of Urban and Regional Research, 24(2), pp. 439-458. doi:10.1111/1468-2427.00256 Retrieved from $<$ Go to ISI>://WOS:000087667500009

http://onlinelibrary.wiley.com/store/10.1111/1468-2427.00256/asset/14682427.00256.pdf? $\mathrm{v}=1 \& \mathrm{t}=\mathrm{h} 0$ wici27\&s $=05 \mathrm{fcc} 0 \mathrm{ae} 1 \mathrm{f} 852725 \mathrm{ea} 524 \mathrm{c} 0 \mathrm{cbac} 100757515 \mathrm{fd} 7 \mathrm{a}$

Hoksbergen, E., \& Insch, A. (2016). Facebook as a platform for co-creating music festival experiences: The case of New Zealand's Rhythm and Vines New Year's Eve festival. International Journal of Event and Festival Management, 7(2), pp. 84-99. doi:doi:10.1108/IJEFM-02-2016-0012 Retrieved from https://www.emeraldinsight.com/doi/abs/10.1108/IJEFM-02-2016-0012

https://www.emeraldinsight.com/doi/pdfplus/10.1108/IJEFM-02-2016-0012

Holloway, L., \& Kneafsey, M. (2000). Reading the space of the farmers' market: A preliminary investigation from the UK. [Article]. Sociologia Ruralis, 40(3), pp. 285-299. doi:10.1111/1467-9523.00149 Retrieved from $<$ Go to ISI $>$ ://WOS:000088352500001

http://onlinelibrary.wiley.com/store/10.1111/1467-9523.00149/asset/14679523.00149.pdf? $\mathrm{v}=1 \& \mathrm{t}=\mathrm{ibj}$ frndn $\& \mathrm{~s}=47073 \mathrm{e} 5 \mathrm{f1496168 \textrm {a } 4 \mathrm { b } 2 5 0 3 \mathrm { bbc } 1 9 \mathrm { c } 1 0 7 \mathrm { d } 6 \mathrm { abb } 5 9 5 \mathrm { b }}$ 
Horbel, C., Popp, B., Woratschek, H., \& Wilson, B. (2016). How context shapes value co-creation: spectator experience of sport events. The Service Industries Journal, 36(11-12), pp. 510-531. doi:10.1080/02642069.2016.1255730 Retrieved from https://doi.org/10.1080/02642069.2016.1255730

https://www.tandfonline.com/doi/full/10.1080/02642069.2016.1255730

Hubbard, P. (2013). Carnage! Coming to a town near you? Nightlife, uncivilised behaviour and the carnivalesque body. [Article]. Leisure Studies, 32(3), pp. 265282. doi:10.1080/02614367.2011.633616 Retrieved from $<$ Go to ISI $>$ ://WOS:000320358500003

http://www.tandfonline.com/doi/pdf/10.1080/02614367.2011.633616

Jeannerat, H. (2013). Staging experience, valuing authenticity: Towards a market perspective on territorial development. European Urban and Regional Studies, 20(4), pp. 370-384. doi:10.1177/0969776412454126 Retrieved from http://eur.sagepub.com/content/20/4/370

Kim, W., \& Walker, M. (2012). Measuring the social impacts associated with Super Bowl XLIII: Preliminary development of a psychic income scale. [Article]. Sport Management Review, 15(1), pp. 91-108. doi:10.1016/j.smr.2011.05.007 Retrieved from $<$ Go to ISI $>$ ://WOS:000208911700009

http://ac.els-cdn.com/S144135231100043X/1-s2.0-S144135231100043Xmain.pdf? tid=0d7b2092-20e9-11e6-bfb600000aab0f6c\&acdnat $=1464009781$ a6feaf05fac93aaf5c367358328278b5

Nicholson, R. E., \& Pearce, D. G. (2001). Why Do People Attend Events: A Comparative Analysis of Visitor Motivations at Four South Island Events. Journal of Travel Research, 39(4), pp. 449-460. doi:10.1177/004728750103900412 Retrieved from http://jtr.sagepub.com/content/39/4/449.abstract

http://jtr.sagepub.com/content/39/4/449

Pennay, A., Manton, E., \& Savic, M. (2014). Geographies of exclusion: Street drinking, gentrification and contests over public space. International Journal of Drug Policy, 25(6), pp. 1084-1093. doi:http://dx.doi.org/10.1016/j.drugpo.2014.06.001 Retrieved from http://www.sciencedirect.com/science/article/pii/S0955395914001479

http://ac.els-cdn.com/S0955395914001479/1-s2.0-S0955395914001479main.pdf? tid=9068d682-2ef6-11e6-ac2300000aacb35f\&acdnat $=1465554900$ d0f361c89b737810b3274e5cb1c4d981

Peperkamp, E., Rooijackers, M., \& Remmers, G.-J. (2015). Evaluating and designing for experiential value: the use of visitor journeys. Journal of Policy Research in Tourism, Leisure and Events, 7(2), pp. 134-149. doi:10.1080/19407963.2014.951938 Retrieved from https://doi.org/10.1080/19407963.2014.951938

Pine, B. J., \& Gilmore, J. H. (2011). The Experience Economy (Updated ed.) Boston, US: Harvard Business School Publishing.

Platt, L., \& Ali-Knight, J. (2018). Guest editorial. Journal of Place Management and Development, 11(3), pp. 262-265. doi:doi:10.1108/JPMD-08-2018-131 Retrieved from https://www.emeraldinsight.com/doi/abs/10.1108/JPMD-082018-131

Powe, N., \& Hart, T. (2008). Market towns: understanding and maintaining functionality. Town Planning Review, 79(4), pp. 347-370. doi:doi:10.3828/tpr.79.4.2 Retrieved from http://online.liverpooluniversitypress.co.uk/doi/abs/10.3828/tpr.79.4.2 
Quinn, B. (2010). Arts festivals, urban tourism and cultural policy. Journal of Policy Research in Tourism, Leisure and Events, 2(3), pp. 264-279. doi:10.1080/19407963.2010.512207 Retrieved from http://dx.doi.org/10.1080/19407963.2010.512207

http://www.tandfonline.com/doi/pdf/10.1080/19407963.2010.512207

Quinn, B., \& Wilks, L. (2013). Festival Connections - People, place and social capital. In G. Richards, M. De Brito \& L. Wilks (Eds.), Exploring the Social Impacts of Events (pp. 15-30). Abingdon: Routledge.

Richards, G., de Brito, M., \& Wilks, L. (2013). Exploring the social impacts of events Abingdon: Routledge.

Richards, G., \& Palmer, R. (2010). Eventful Cities: Cultural Management and Urban Revitalisation Oxford: Butterworth-Heinemann.

Robson, C., \& McCartan, K. (2016). Real World Research (4th ed.) Chichester: John Wiley \& Sons.

Romero, D., \& Molina, A. (2011). Collaborative networked organisations and customer communities: value co-creation and co-innovation in the networking era.

Production Planning \& Control, 22(5-6), pp. 447-472.

doi:10.1080/09537287.2010.536619 Retrieved from https://doi.org/10.1080/09537287.2010.536619

https://www.tandfonline.com/doi/pdf/10.1080/09537287.2010.536619?needAccess $=$ tru

$\underline{\mathrm{e}}$

Rust, E. L. (2017). The Impacts of Small-scale Cultural Events on Market Town Vitality (Ph.D). University of Southampton, Southampton.

Silverman, D. (2011). Interpreting Qualitative Data: A Guide to the Principles of Qualitative Research (4th ed.) London: Sage Publications Ltd.

Slater, A., \& Wood, E. H. (Eds.). (2015). The Festival \& Event Experience: L S A Publications.

Stake, R. E. (2000). The Case Study Method in Social Inquiry. In M. Hammersley, R. Gomm \& P. Foster (Eds.), Case Study Method (pp. 19-26). London: Sage Publications Ltd.

Swyngedouw, E., Moulaert, F., \& Rodriguez, A. (2002). Neoliberal urbanization in Europe: Large-scale Urban Development Projects and the New Urban Policy. Antipode, 34(3), pp. 542-577. doi:10.1111/1467-8330.00254 Retrieved from $<$ Go to ISI $>$ ://WOS:000177192100010

http://onlinelibrary.wiley.com/store/10.1111/1467-8330.00254/asset/1467-

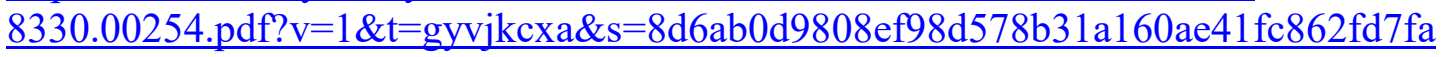

Szmigin, I., Bengry-Howell, A., Morey, Y., Griffin, C., \& Riley, S. (2017). Sociospatial authenticity at co-created music festivals. Annals of Tourism Research, 63, pp. 1-11. doi:http://dx.doi.org/10.1016/j.annals.2016.12.007 Retrieved from http://www.sciencedirect.com/science/article/pii/S0160738316301761

Tope, D., Chamberlain, L. J., Crowley, M., \& Hodson, R. (2005). The Benefits of Being There. Journal of Contemporary Ethnography, 34(4), pp. 470-493. doi:10.1177/0891241605276692 Retrieved from http://journals.sagepub.com/doi/abs/10.1177/0891241605276692

http://journals.sagepub.com/doi/10.1177/0891241605276692

Van Niekerk, M. (2017). Contemporary issues in events, festivals and destination management. [Article]. International Journal of Contemporary Hospitality Management, 29(3), pp. 842-847. doi:10.1108/IJCHM-01-2017-0031 Retrieved from 
http://search.ebscohost.com/login.aspx?direct=true \&db=bth\&AN=122094401\& $\underline{\text { site }=\text { eds-live }}$

https://www.emeraldinsight.com/doi/abs/10.1108/IJCHM-01-2017-0031

Waitt, G. (2000). Consuming heritage: Perceived historical authenticity. Annals of Tourism Research, 27(4), pp. 835-862. doi:http://dx.doi.org/10.1016/S01607383(99)00115-2 Retrieved from

http://www.sciencedirect.com/science/article/pii/S0160738399001152

http://ac.els-cdn.com/S0160738399001152/1-s2.0-S0160738399001152-

main.pdf? tid=fa3e4f22-b256-11e6-b06f-

00000aab0f6c\&acdnat $=1479999911 \quad 69 \mathrm{ab} 1088$ bae957d2efa672fade 544870

Zukin, S. (2008). Consuming authenticity - From outposts of difference to means of exclusion. [Article]. Cultural Studies, 22(5), pp. 724-748.

doi:10.1080/09502380802245985 Retrieved from

http://www.tandfonline.com/doi/pdf/10.1080/09502380802245985 
Tables

Table 1. Combined number of respondents.

\begin{tabular}{|l|r|}
\hline Data source & Number \\
\hline Visitor surveys & 334 \\
\hline Business surveys & 102 \\
\hline Trader/performer surveys & 75 \\
\hline Residents' surveys & 253 \\
\hline Interviews & 14 \\
\hline Combined total & 778 \\
\hline
\end{tabular}


Table 2. Phases of thematic coding analysis (adapted from Robson and McCartan, 2016, p469)

\begin{tabular}{|l|l|}
\hline Phase & Action \\
\hline 1. Data familiarisation & $\begin{array}{l}\text { Data transcription, reading and re- } \\
\text { reading. }\end{array}$ \\
\hline 2. Generation of initial codes & $\begin{array}{l}\text { Inductive interaction with the data. } \\
\text { Similar data given similar codes. }\end{array}$ \\
\hline 3. Identification of themes & $\begin{array}{l}\text { Grouping of complementary codes into } \\
\text { potential themes. }\end{array}$ \\
\hline 4. Construction of thematic networks & Development of a thematic 'map'. \\
\hline 5. Integration and interpretation & $\begin{array}{l}\text { Exploration, summarising and } \\
\text { interpretation of the patterns and themes. }\end{array}$ \\
\hline
\end{tabular}




\section{Figures}

Figure 1. The Beggars Fair, Romsey

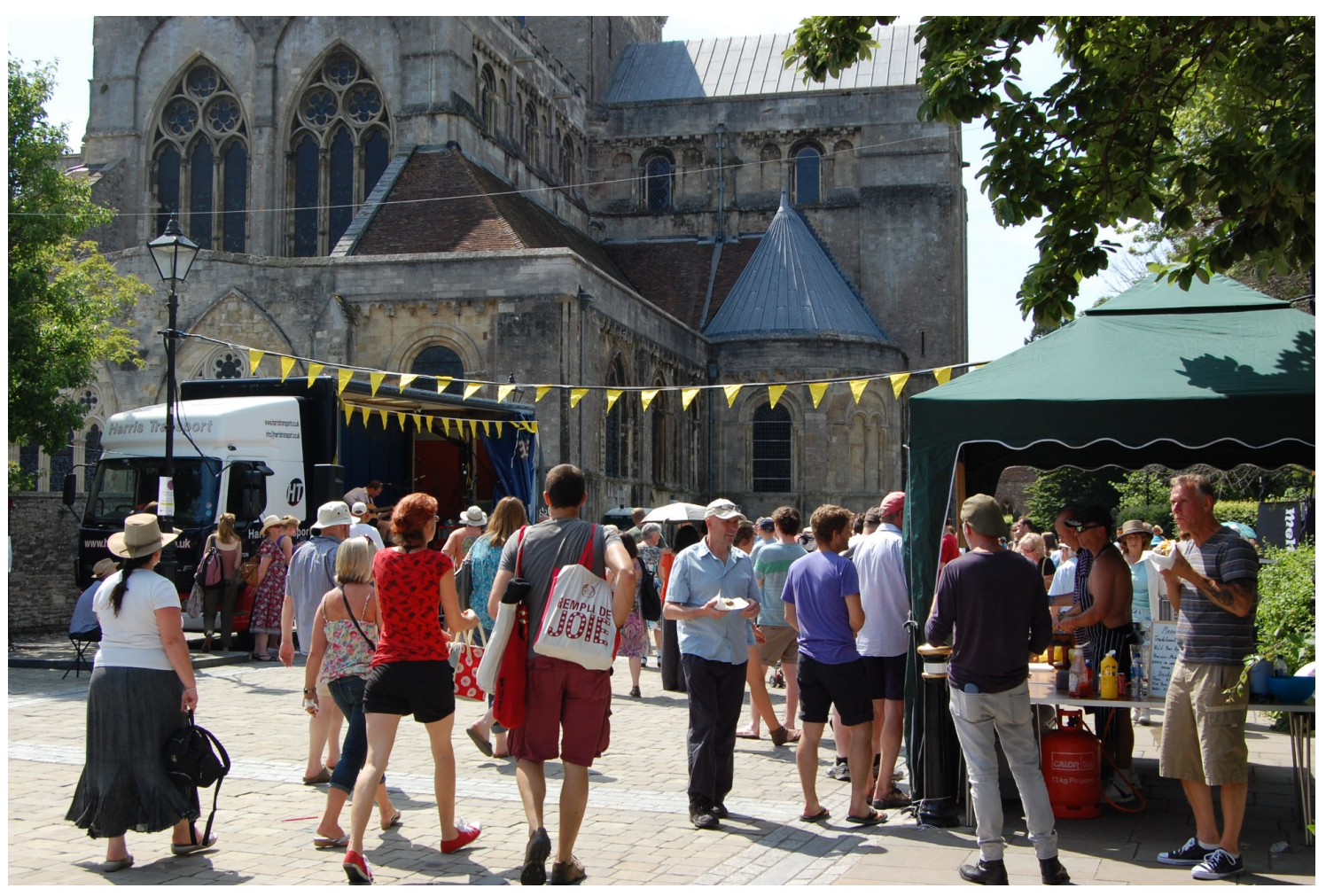


Figure 2. Trout 'n About, Stockbridge

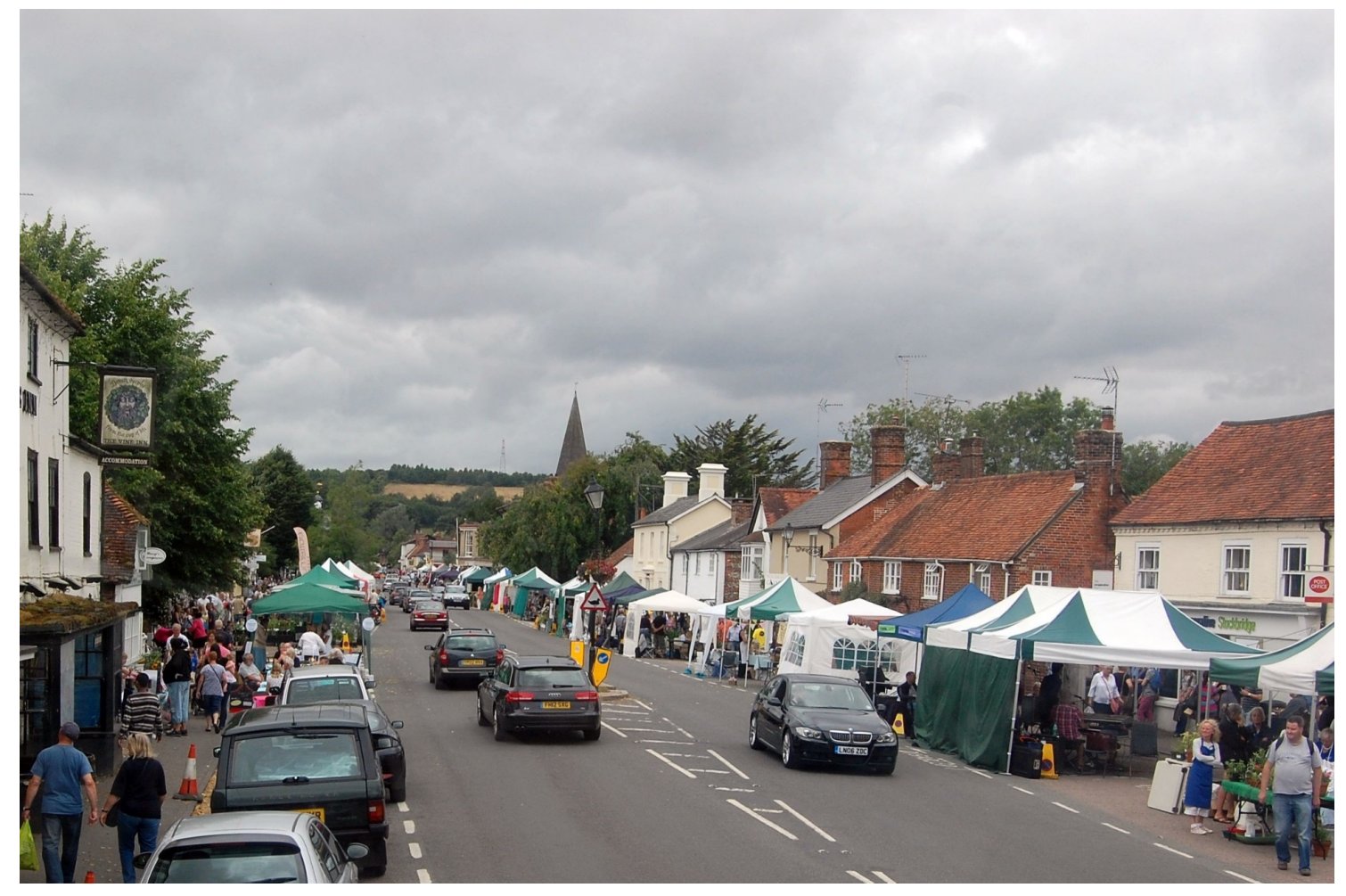


Figure 3. Andover farmers' and crafts market

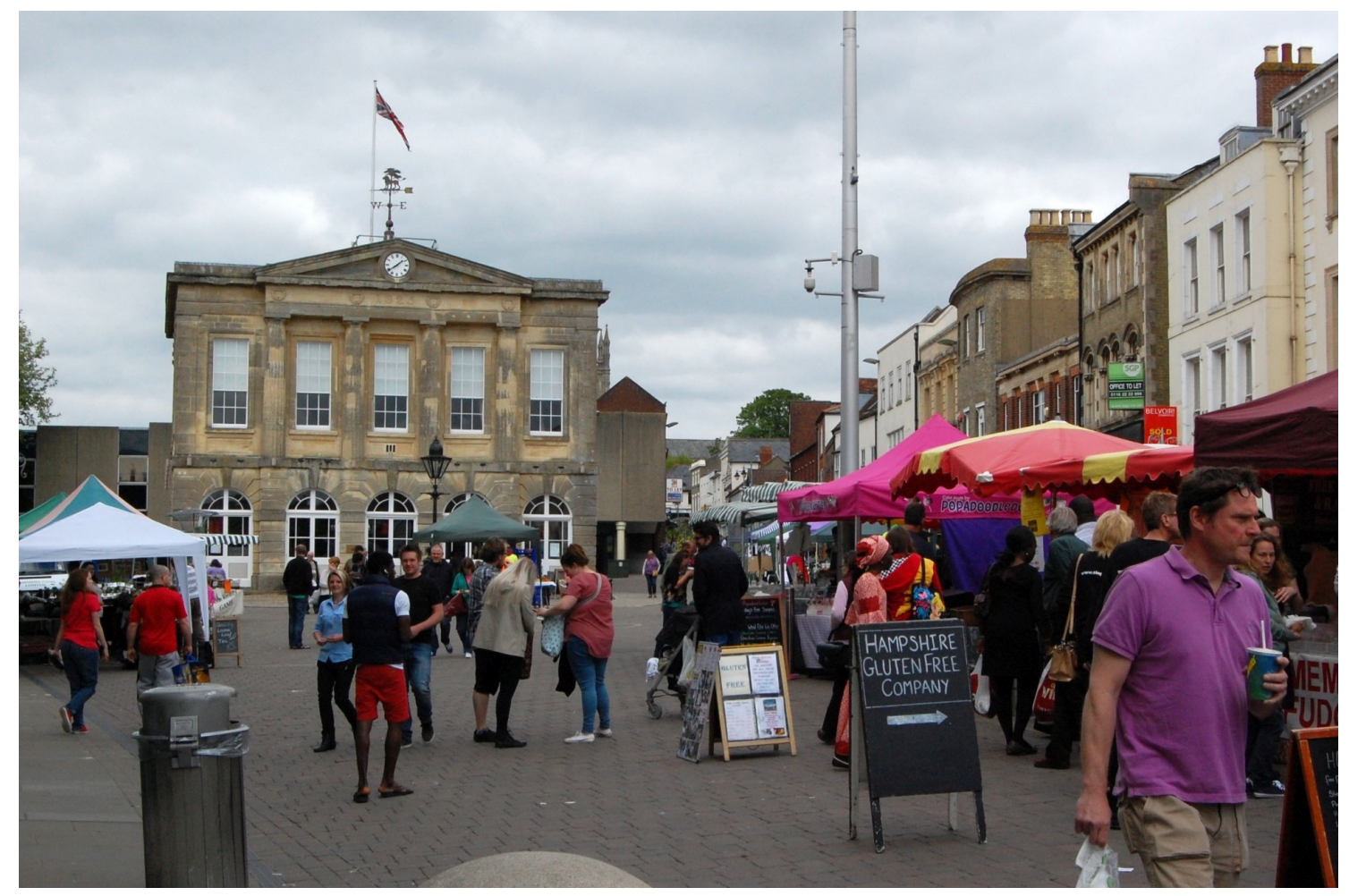

